\title{
Large animal models and gene therapy
}

\author{
Margret Casal $^{1}$ and Mark Haskins*,1 \\ ${ }^{1}$ School of Veterinary Medicine, University of Pennsylvania, Philadelphia, PA, USA
}

Over the last two decades, gene transfer experiments for the treatment of inherited or acquired diseases have mainly been performed in mice. While mice provide proof of principle and allow testing of a variety of therapeutic modalities, mouse models have some limitations, as only short-term experiments can be performed, their homogenous genetic background is unlike humans, and the knockout models do not always faithfully represent the human disease. Naturally occurring large animal models of human genetic diseases have become increasingly important despite the costs and the extensive clinical attention they require because of their similarities to human patients. Large animals are reasonably outbred, long lived allowing for longitudinal studies, are more similar in size to a neonate or small child providing an opportunity to address issues related to scaling up therapy, and many physiological parameters including the immune system are more similar to those in humans versus those in mice.

European Journal of Human Genetics (2006) 14, 266-272. doi:10.1038/sj.ejhg.5201535; published online 7 December 2005

Keywords: animal models; gene therapy; viral vectors

\section{Introduction}

Most diseases that are currently viewed as candidates for gene therapy are caused by mutations resulting in the absence of a particular protein (eg enzyme deficiencies) or are the result of dysregulation/failure of controlled cell growth (ie cancer). The most common current gene transfer approach to providing tissues with a therapeutic protein is to administer normal cDNA to express the missing protein, or in the case of cancer to either provide 'suicide genes' or antitumor factors. These approaches usually involve using a viral vector to transfer the cDNA, which may either integrate into the chromosomal DNA of the patient's cells or may remain episomal, or both. A vast number of experiments have been performed in mice and other species to develop clever methods of gene transfer. However, as has been seen in recent human clinical trials, ${ }^{1,2}$ there are important safety concerns, which need to be addressed. Therefore, gene transfer studies with

*Correspondence: Professor M Haskins, School of Veterinary Medicine, University of Pennsylvania, 3800 Spruce Street, Philadelphia, PA 191046051, USA. Tel: + 1215898 4852; Fax: + 1215898 0719;

E-mail: mhaskins@vet.upenn.edu

Received 5 August 2005; revised 23 September 2005; accepted 14 October 2005; published online 7 December 2005 statistically and rationally meaningful outcomes need to be evaluated in models that closely resemble the human diseases.

Mice have been invaluable for the study of gene transfer methods and gene therapy of inherited diseases. They are inexpensive to keep, their generation time is short, and they have large litters. Today's transgenic technologies allow the development of almost any monogenetic disease model in the mouse and the various mouse strains are highly inbred, providing uniform conditions in which experiments can be easily reproduced and statistical significance achieved. ${ }^{3}$ However, mouse models may fail to faithfully mirror the human disease ${ }^{4,5}$ and longitudinal studies are not possible because of their short lifespan. Thus, large animal models of human genetic diseases complement the murine studies because they have a longer lifespan, are more similar in size to a neonate or child, their background genetic heterogeneity is similar to that of humans, and they are genetically more closely related to humans than mice. ${ }^{6,7}$ Scaling up issues can also be addressed in large animals; there is a 1000-fold size difference between a mouse and newborn child's brain but only 10-fold between a small dog and a neonatal human. Also, because of their longevity and size, more 
samples from an individual over time can be obtained to determine long-term efficacy and safety of a given therapy.

Large animal models clearly represent an important step in the preclinical evaluation of human-directed gene transfer protocols. Dogs and cats are the most commonly used species. Some larger species have been used in the past to better understand genetic diseases, but considerations of size, housing, and reproduction have limited their use in treatment protocols. Sheep ${ }^{8,9}$ and non-human primates ${ }^{10}$ are often used for the development of gene transfer techniques, gene marking studies, and assessment of safety, but despite the existence of genetic diseases in these species, they have not yet been used for treatment trials. Other large animal models, such as pigs or horses, are almost exclusively used to study treatment of induced diseases, such as cardiovascular disease and arthritis, respectively. The list of large animal models of human diseases has become quite long and continues to increase. ${ }^{11}$ Examples of large animal models used for gene therapy are highlighted below.

\section{Canine models}

The dog is the most widely used experimental large animal for therapeutic gene transfer studies of naturally occurring genetic diseases. To date, over 350 genetic diseases have been described in the dog, many of which are analogous to human genetic diseases. ${ }^{12,13}$ Dogs have been invaluable for the understanding of both disease pathogenesis and a variety of therapies. ${ }^{12}$ Over $58 \%$ of genetic diseases present in the dog are true orthologues of human diseases caused by mutations in the same genes. ${ }^{14}$ In addition to the obvious longevity and similarity in size to a small child, many parts of the canine immune system are much more similar to those of the human than the murine immune system. ${ }^{15}$ The wide diversity of dog breeds and breeding practices have led to a large number of distinct and isolated genetic populations. This combined with exponential advances in canine genetics in recent years has led to the identification and characterization of numerous canine genetic disorders, many of which exist in research colonies. ${ }^{16,17}$

Mucopolysaccharidosis VII (MPS VII), caused by deficient activity of beta-glucuronidase (GUSB), was first described in a child in $1973 .^{18}$ This lysosomal storage disease has multisystemic manifestations including organomegaly, and skeletal, central nervous system (CNS), cardiovascular, and ocular abnormalities. ${ }^{19}$ The first animal model of MPS VII was described from German shepherd dogs in 1984 at the University of Pennsylvania. ${ }^{20}$ The murine ${ }^{21}$ and feline MPS VII models were subsequently described. ${ }^{22-24}$ For the murine, canine, and feline models, the cDNA sequences are known, and the mutations have been identified. ${ }^{22,25,26}$ Treatment of lysosomal storage diseases is based on cross- correction; the ability of the normal enzyme to be taken up by deficient cells. ${ }^{27}$

Intravenous delivery of recombinant adeno-associated virus (rAAV) vectors in MPS VII mice resulted in substantial correction of disease and included normalization or significant improvements of body growth, retinal morphology and function, auditory deficits, skeletal abnormalities, and lifespan with stable enzyme activity for at least 1 year post treatment. ${ }^{28}$

Insights from this experiment led to testing intravenous retroviral (RV) vectors in neonatal dogs, which showed that the natural hepatocellular division in the canine neonatal period was sufficient for significant RV integration. ${ }^{29}$ This preliminary step was followed by neonatal, intravenous, RV gene therapy in dogs and mice with MPS VII, which yielded impressive clinical and pathological results. ${ }^{30-33}$ The series of canine experiments involved treatment of dogs at days 2-3 of life. These dogs, treated with the canine cDNA, have had stable serum GUSB activity of between 40 and $6000 \%$ of normal for up to the current 5 years. Important clinical signs of disease, such as cardiac abnormalities, were absent or minimal. ${ }^{32}$ There was marked improvement in the growth of treated dogs, and the skeletal disease was improved in the limbs. ${ }^{30,31}$ The dogs have remained ambulatory to 5 years, versus untreated affected dogs, which are unable to stand or walk by the age of 6 months. Corneal clouding has been absent or very mild in all treated dogs. To date, no offspring, of over 180 evaluated, possess the transgene, and no transgene has been detected in sperm from the treated males (Haskins, unpublished data). In addition to the transduction of up to $20 \%$ of hepatocytes, preliminary results showed this treatment to have also transduced hematopoetic stem cells, as peripheral white blood cells have remained vectorand GUSB expression-positive for 4.5 years. ${ }^{34}$ In a preliminary result from MPS VII dogs treated later, at 7 weeks of age, with and without hepatocyte growth factor, serum GUSB activity was stable at $14-83 \%$ of normal, which was impressive, but little reduction in clinical disease was seen. The percent of normal enzyme activity in peripheral white blood cells containing vector sequence was very low ${ }^{35}$ compared to the neonatally treated dogs, which may help explain the apparent superiority of the earlier treatment.

\section{Hemophilia}

Hemophilia A and B are X-linked inherited bleeding disorders caused by a deficiency of the blood clotting protein factors VIII (FVIII) and IX (FIX), respectively. These factors are normally synthesized in the liver and secreted into blood. Current treatment of hemophilia involves infusions of plasma-derived or recombinant clotting factor in response to bleeding crises. Hemophilias are particular attractive disorders for the development of gene-based therapies as conventional therapy is life long, expensive, patients remain at risk for emerging blood-borne infectious 
diseases, and therapy is in response to a bleeding crisis, not to prevent them. Finally, therapeutic control of hemostasis can be accomplished by supplying a small percentage of normal factor levels, particularly in Hemophilia A, making gene transfer-based therapies achievable. The canine models of hemophilia have been useful for developing and evaluating gene therapies because the canine proteins are very well characterized, the genes have been cloned,,$^{3,36-45}$ and cDNAs are available. Moreover, in contrast to many diseases, there is no requirement for a specific target tissue for gene delivery, and the gene product itself does not require precise regulation of expression. Hemophilia $\mathrm{B}$ is highlighted here as an example of gene therapy for a bleeding disorder.

Administration of an adenovirus vector with the canine FIX cDNA via the portal vein directly to the liver produced plasma FIX concentrations in hemophilia B dogs ranging from 0 to $300 \%$ of the level present in normal dogs. ${ }^{46}$ This resulted in amelioration of the disease demonstrated by normal blood coagulation and hemostatic measurements. However, as is typical with adenoviral vectors, the activity then declined due to an immune response. ${ }^{46}$

The experiments with the most encouraging results were those using serotype 2 AAV vectors delivered by percutaneous injections into skeletal muscle. Five hemophilia B dogs with a missense mutation were treated with the canine cDNA and showed stable ( $>17$ months) vector dose-dependent partial correction of the whole blood clotting time and, at higher doses, of the activated partial thromboplastin time. ${ }^{47}$ Treating hemophilia B dogs carrying a null mutation for FIX resulted in the induction of inhibitory anti-canine FIX antibodies. However, treatment with a combination of gene transfer and transient immune modulation resulted in sustained expression ( $>8$ months) at levels sufficient for partial correction of coagulation parameters. ${ }^{48}$ The intramuscular approach was shown to be dose-dependent. ${ }^{49}$ However, large doses of vector in single sites produced anti-FIX antibodies. ${ }^{50} \mathrm{~A}$ novel alternate approach used an intravascular isolated limb delivery technique to achieve extensive transduction of most of the muscle in the dog limb, resulting in long-term $(>3$ years, with observation ongoing), robust FIX expression (circulating levels of $4-14 \%$ of normal), and essentially complete correction of the bleeding disorder. ${ }^{51}$

Intravenous and portal vein administration of AAV vectors producing transduction of hepatocytes resulted in up to $14 \%$ of normal canine FIX levels, the absence of inhibitors, and a sustained partial correction of the coagulation defect. ${ }^{52-55}$ However, one dog with a null mutation showed transient expression (4 weeks) and the development of neutralizing anti-canine FIX inhibitory antibodies. $^{55}$ In a third approach, an RV vector was administered intravenously to three newborn hemophilia B dogs, resulting in hepatocyte transduction, $12-36 \%$ of normal canine FIX levels, and improved coagulation tests.
Two dogs with null mutations failed to generate antibodies to canine FIX, demonstrating that neonatal gene transfer may have induced tolerance. ${ }^{56}$

Congenital stationary night blindness was first described in the Briard breed and is characterized by early retinal degeneration with clinical signs ranging from normal day vision to complete blindness. ${ }^{57}$ The disease is orthologous to Leber congenital amaurosis in humans and is caused by a 4-bp deletion in the RPE65 gene in $\operatorname{dogs}^{58}$ that truncates the normal protein, resulting in undetectable levels of the visual pigment rhodopsin, which is required for normal vision. Briard dogs with a mutation in RPE65 have early and severe visual impairment. Histopathological examination of the retinas of dogs homozygous for the RPE65 mutation showed prominent inclusions in the RPE and a slightly abnormal morphology of rods early in life, with slowly progressive degeneration of the photoreceptors. ${ }^{59}$

AAV vectors were administered subretinally or intravitreally to three affected dogs. ${ }^{60}$ This approach placed the vector in direct contact with the cells of the RPE. The treated dogs were evaluated and compared to untreated affected dogs using electroretinography (ERG) and by setting up obstacle courses in subdued lighting. ERG testing showed improvement in treated eyes compared with the same eyes prior to treatment and when compared with the untreated contralateral eye. As expected, retinal function did not completely return to normal, as the injection of vector targeted only about 35\% of the retina. Injection of the vector into the vitreous body did not improve retinal function. ${ }^{60}$ Importantly, the results of qualitative (behavioral) assessments of visual function conducted 4 months after treatment were consistent with the ERG findings. The treated dogs were scored as 'normally sighted' under room lighting: they consistently avoided objects placed directly in front of them and on the treated side, but failed to avoid objects placed on the untreated side. ${ }^{60}$ The oldest treated animal has remained visually stable for 5 years (Acland, personal communication).

\section{Neoplasia}

Many cancers in the dog occur at higher frequencies in certain breeds and can be traced through specific lineages within a breed suggesting hereditary components. Other cancers, such as mammary cancers, are very common but do not have a specific breed predilection. Several clinical trials have been attempted to treat hereditary or spontaneous forms of canine neoplasia. ${ }^{61-66}$ Experiments in the treatment of canine oral melanomas are highlighted here because, despite some differences, the overall biological behavior of malignant melanoma is very similar in dogs and humans, making the dog an ideal model for development of therapy.

Oral melanomas in the dog are almost always malignant. Dogs with stage III melanoma have a short median survival 
time of 4-5 months, and without surgical resection the tumor will lead to death because $85-90 \%$ of the tumors metastasize. ${ }^{67}$ In a clinical trial for canine oral melanoma, liposomes conjugated to Fas-ligand (FasL) DNA were injected directly into the tumors to induce apoptosis. ${ }^{61}$ Tumor regression of $12.5-58 \%$ was observed in three of five patients (one dog showed stable disease, and tumor size could not be evaluated in the fifth dog). No local or systemic adverse effects were observed over the course of the 7-day observation period. At 7 days after intratumoral therapy, the study dogs were given standard treatment for their tumors (surgery, radiation, or palliation). Two dogs went into complete remission until they died of unrelated causes at 24 and 44 weeks post therapy. Two dogs achieved partial remission; one died 13 weeks later of an unrelated cause. The disease progressed in the other dog 42 weeks after treatment, was surgically debulked and the dog lived for 82 weeks after gene therapy, at which time it died of its melanoma. ${ }^{61}$ Fas-L expression in tumor cells obtained from those dogs with the best responses to therapy was present but was not detected in those cells from dogs with little or no response to treatment. ${ }^{61}$

In another experiment, 26 dogs with malignant melanoma received intratumoral injections of lipid-complexed plasmid DNA encoding a bacterial superantigen and one of two cytokines (IL-2 or GM-CSF). ${ }^{63}$ No side effects were noted and partial or complete remission was achieved in $12 / 26$ treated dogs. Interestingly, the authors observed high levels of antitumor cytotoxic T-cell activity in the peripheral blood indicating that local administration of the vector may have produced a systemic effect. ${ }^{63}$

\section{Feline models}

Cats are of particular interest for neurological disorders, as the cat brain has been very well characterized both functionally and physiologically. The anatomy of the cat brain is also more similar to that of a human than that of a mouse. ${ }^{68,69}$

\section{Feline alpha-mannosidosis (AMD) $)^{70,71}$}

Mannosidosis is a glycoprotein storage disease caused by a deficiency of lysosomal acidic alpha-mannosidase and results in the lysosomal accumulation of mannose-rich oligosaccharides. The mutation in the feline model is a 4 base pair deletion, leading to a frame shift and premature termination codon. ${ }^{72}$ Affected cats exhibit generalized action tremors, intention tremors of the head and neck, loss of balance, nystagmus, spinal ataxia, and dysmetria, and histologically have widespread neuronal storage. All signs are progressive and euthanasia is usually performed between 18 and 20 weeks of age for humane reasons. As with other lysosomal storage diseases, enzyme released from genetically corrected cells can be taken up by mutant cells, and a small amount of normal enzyme is sufficient to correct storage lesions. Heterologous bone marrow transplantation yielded dramatic results in the treatment of the CNS disease of cats with AMD, even though therapy was begun when mild clinical signs were present. ${ }^{73}$ To test the efficacy of gene transfer, 8-week-old kittens affected with AMD received multiple intracranial injections of rAAV expressing the normal feline alpha-mannosidase cDNA. ${ }^{74}$ The injections were performed at a time at which there was already clinical evidence of mild disease in the kittens. Physical and neurological examination after gene therapy revealed remarkable clinical improvement compared to untreated controls. At 18 weeks of age, the cats showed only mild signs of disease, while euthanasia was necessary in the untreated littermates because of the severity of neurological signs. One cat was followed out to 30 weeks of age when it developed clinical signs comparable to those seen at 18 weeks in untreated affected cats. Another treated cat never showed any disease progression from 18 weeks of life until euthanasia at 56 weeks of life. Magnetic resonance imaging also demonstrated improvement in brain myelination after treatment. Enzyme activity measured in whole brain sections was about $4 \%$ of normal. Storage lesions were markedly reduced throughout the whole brain, despite the fact that in situ hybridization showed mRNA only around injections tracks. ${ }^{74}$

\section{Equine models}

The horse is most commonly used as a model for osteoarthritis because the disease occurs naturally in this species. $^{75}$ Surprisingly though, virtually all of the gene transfer experiments have been performed in induced rather than natural models. ${ }^{76,77}$ While there are a number of naturally occurring diseases in the horse, to our knowledge only melanoma has been used in gene therapy experiments.

Melanoma occurs in $80 \%$ of gray horses older than 12 years of age. Interestingly, they are encapsulated and metastases occur infrequently early in the course of disease, which is in contrast to human malignant melanoma. ${ }^{78}$ However, the histologic features and immunostaining results show extensive similarity to the human tumors, making the gray horse, like the dog, an attractive model to investigate treatments. ${ }^{78}$ A total of 12 metastatic lesions on seven horses were injected with plasmid DNA coding for human interleukin-12. ${ }^{79}$ No side effects of the treatment were observed. Three intralesional treatments spaced 2 weeks apart resulted in tumor size reduction, ranging from complete resolution to a slight increase in size in one animal. On average, the tumors decreased to $41 \%$ of their original size, whereas the untreated tumors increased slightly in size $(107 \%)$ during the same time period. ${ }^{79}$ Once the tumors had decreased in size and the treatment was discontinued, the tumors slowly grew larger but 
decreased again in response to an additional round of treatment with the plasmid DNA. ${ }^{79}$ Histological evaluation of biopsies taken from the treated lesions revealed an influx of mainly CD4 but also CD8 lymphocytes around the tumors, which was never observed in the untreated control tumors.

\section{Bovine models}

Cattle are rarely used for gene therapy experiments, probably because of their size and, thus, the expense of scaling up viral vectors or recombinant protein preparations. However, calves weigh about $30-35 \mathrm{~kg}$ at birth, about the same as a child, making them a good model to address scaling up issues for therapies designed for older children. There are few animal models of urea cycle defects and to our knowledge there is no large animal model of citrullinemia, other than the established bovine model described below. ${ }^{80}$

Citrullinemia is a urea cycle disorder characterized by hyperammonemia and is caused by a nonsense mutation ( $\mathrm{C}$ to $\mathrm{T}$ transition) in the gene coding for argininosuccinate synthetase in cattle. ${ }^{81}$ While many of the clinical signs can be controlled by dietary restriction of proteins, additional illness or other stressors can easily result in hyperammonemia. ${ }^{82}$ Citrullinemia in newborn Friesian calves is characterized by progressive neurological signs after their first feeding and subsequent death within the first few days of life. ${ }^{80}$

Two neonatal calves were genotyped at birth and supplemented (arginine/benzoate) to prevent hyperammonemia and death. ${ }^{83}$ At 8 days of life, the affected calves received an E1a-deleted adenovirus containing the human argininosuccinate synthetase cDNA intravenously. The effect of gene therapy was monitored both clinically and biochemically. Radioactively labeled ammonium chloride $\left({ }^{15} \mathrm{~N}\right)$ was given every $6 \mathrm{~h}$ over a period of 2 days before and on days 2-3 and 16-17 after vector treatment. Before treatment, glutamine levels exceeded those of normal calves by up to three-fold. Radioactive glutamine and plasma citrulline concentrations decreased in both treated calves to virtually normal levels indicating normal urea synthesis, which lasted for at least 18 days after treatment. Biochemical liver values were also measured to evaluate the safety of the vector. A week after administration of the adenovirus, both calves had elevated serum aspartate aminotransferase concentrations. All other liver parameters remained normal at all time points. Finally, there were no signs of inflammation by histological examination of the calves' liver 18 days after therapy, suggesting that the adenoviral therapy was safe. ${ }^{83}$ Clearly, more studies will need to be performed, as only two calves received the vector and the last evaluation was done only 18 days after treatment.

\section{Conclusions}

Many of the gene transfer studies performed to date in large animals, especially sheep and non-human primates, have been done using normal animals and have been directed towards improving techniques. However, to fully understand and treat genetic diseases in human patients, the use of authentic animal models are required in studies that for ethical and practical reasons are not possible in humans. The large animals that have been used in gene therapy studies have been selected based on several factors: (1) the animals had similar clinical signs to affected humans, demonstrating similar genetic mechanisms underlying the diseases in both species; (2) their size, which was similar to that of neonates and children; and (3) their long lifespan, which should enable the detection of limitations to therapy. Thus, large animals provide the translational bridge from in vitro and mouse experiments to human patients. Many of the genetic disorders in large animal models that are available today are rare diseases but they often represent an entire class of diseases, such as lysosomal storage diseases, urea cycle defects, and neoplasia. Experiments in these models provide proof of principal for a given disease group and help to define the potential therapeutic efficacy and safety of gene transfer.

\section{Acknowledgements}

This work was supported by a grant from the NIH (RRO2512).

\section{References}

1 Hacein-Bey-Abina S, von Kalle C, Schmidt $M$ et al: A serious adverse event after successful gene therapy for X-linked severe combined immunodeficiency. $N$ Engl J Med 2003; 348: 255-256.

2 Raper SE, Chirmule N, Lee FS et al: Fatal systemic inflammatory response syndrome in a ornithine transcarbamylase deficient patient following adenoviral gene transfer. Mol Genet Metab 2003; 80: $148-158$.

$3 \mathrm{Gu} \mathrm{W}$, Brooks M, Catalfamo J, Ray J, Ray K: Two distinct mutations cause severe hemophilia B in two unrelated canine pedigrees. Thromb Haemost 1999; 82: 1270-1275.

4 Ohshima T, Murray GJ, Swaim WD et al: Alpha-galactosidase A deficient mice: a model of Fabry disease. Proc Natl Acad Sci USA 1997; 94: 2540-2544.

5 Phaneuf D, Wakamatsu N, Huang JQ et al: Dramatically different phenotypes in mouse models of human Tay-Sachs and Sandhoff diseases. Hum Mol Genet 1996; 5: 1-14.

6 Abkowitz JL, Persik MT, Catlin SN, Guttorp P: Simulation of hematopoiesis: implications for the gene therapy of lysosomal enzyme disorders. Acta Haematol 1996; 95: 213-217.

7 Abkowitz JL, Persik MT, Shelton GH et al: Behavior of hematopoietic stem cells in a large animal. Proc Natl Acad Sci USA 1995; 92: $2031-2035$.

8 Lucas ML, Seidel NE, Porada CD et al: Improved transduction of human sheep repopulating cells by retrovirus vectors pseudotyped with feline leukemia virus type C or RD114 envelopes. Blood 2005; 106: 51-58.

9 Porada CD, Park P, Almeida-Porada G, Zanjani ED: The sheep model of in utero gene therapy. Fetal Diagn Ther 2004; 19: 23-30.

10 Donahue RE, Dunbar CE: Update on the use of nonhuman primate models for preclinical testing of gene therapy approaches targeting hematopoietic cells. Hum Gene Ther 2001; 12: 607-617. 
11 Nicholas FW: Online Mendelian Inheritance in Animals (OMIA): a comparative knowledgebase of genetic disorders and other familial traits in non-laboratory animals. Nucleic Acids Res 2003; 31: $275-277$.

12 Patterson DF, Haskins ME, Jezyk PF et al: Research on genetic diseases: reciprocal benefits to animals and man. J Am Vet Med Assoc 1988; 193: 1131-1144.

13 Sargan DR: IDID: inherited diseases in dogs: web-based information for canine inherited disease genetics. Mamm Genome 2004; 15: 503-506.

14 Ostrander EA, Giniger E: Semper fidelis: what man's best friend can teach us about human biology and disease. Am J Hum Genet 1997; 61: 475-480.

15 Felsburg PJ, Somberg RL, Hartnett BJ, Henthorn PS, Carding SR: Canine X-linked severe combined immunodeficiency. A model for investigating the requirement for the common gamma chain (gamma c) in human lymphocyte development and function. Immunol Res 1998; 17: 63-73.

16 Ellinwood NM, Casal ML, Haskins ME: Gene therapy for metabolic inherited diseases in dogs; In: Eds OEA, Giger U, Lindblad-Toh K (eds): Cold Spring Harbor Monograph The Dog and Its Genome. NY: Cold Spring Harbor Press, 2005; 473-495.

17 Ellinwood NM, Vite CH, Haskins ME: Gene therapy for lysosomal storage diseases: the lessons and promise of animal models. J Gene Med 2004; 6: 481-506.

18 Sly WS, Quinton BA, McAlister WH, Rimoin DL: Beta glucuronidase deficiency: report of clinical, radiologic, and biochemical features of a new mucopolysaccharidosis. J Pediatr 1973; 82: 249-257.

19 Neufeld EF, Meunzer J: The Mucopolysaccharidoses; In: Scriver CR, Beaudet AL, Sly WS, Valle D (eds): Metabolic and Molecular Basis of Inherited Disease. New York: McGraw Hill, 2001, pp 3421-3452.

20 Haskins ME, Desnick RJ, DiFerrante N, Jezyk PF, Patterson DF: Beta-glucuronidase deficiency in a dog: a model of human mucopolysaccharidosis VII. Pediatr Res 1984; 18: 980-984.

21 Birkenmeier EH, Davisson MT, Beamer WG et al: Murine mucopolysaccharidosis type VII. Characterization of a mouse with beta-glucuronidase deficiency. J Clin Invest 1989; 83: $1258-1266$.

22 Fyfe JC, Kurzhals RL, Lassaline ME et al: Molecular basis of feline beta-glucuronidase deficiency: an animal model of mucopolysaccharidosis VII. Genomics 1999; 58: 121-128.

23 Gitzelmann R, Bosshard NU, Superti-Furga A et al: Feline mucopolysaccharidosis VII due to beta-glucuronidase deficiency. Vet Pathol 1994; 31: 435-443.

24 Schultheiss PC, Gardner SA, Owens JM, Wenger DA, Thrall MA: Mucopolysaccharidosis VII in a cat. Vet Pathol 2000; 37: $502-505$.

25 Ray J, Bouvet A, DeSanto C et al: Cloning of the canine betaglucuronidase cDNA, mutation identification in canine MPS VII, and retroviral vector-mediated correction of MPS VII cells. Genomics 1998; 48: 248-253.

26 Sands MS, Birkenmeier EH: A single-base-pair deletion in the beta-glucuronidase gene accounts for the phenotype of murine mucopolysaccharidosis type VII. Proc Natl Acad Sci USA 1993; 90: $6567-6571$

27 Neufeld EF: The biochemical basis for mucopolysaccharidoses and mucolipidoses. Prog Med Genet 1974; 10: 81-101.

28 Daly TM, Vogler C, Levy B, Haskins ME, Sands MS: Neonatal gene transfer leads to widespread correction of pathology in a murine model of lysosomal storage disease. Proc Natl Acad Sci USA 1999; 96: $2296-2300$.

$29 \mathrm{Xu}$ L, Haskins ME, Melniczek JR et al: Transduction of hepatocytes after neonatal delivery of a Moloney murine leukemia virus based retroviral vector results in long-term expression of betaglucuronidase in mucopolysaccharidosis VII dogs. Mol Ther 2002; 5: $141-153$

30 Mango RL, Xu L, Sands MS et al: Neonatal retroviral vectormediated hepatic gene therapy reduces bone, joint, and cartilage disease in mucopolysaccharidosis VII mice and dogs. Mol Genet Metab 2004; 82: 4-19.

31 Ponder KP, Melniczek JR, Xu L et al: Therapeutic neonatal hepatic gene therapy in mucopolysaccharidosis VII dogs. Proc Natl Acad Sci USA 2002; 99: 13102-13107.

32 Sleeper MM, Fornasari B, Ellinwood NM et al: Gene therapy ameliorates cardiovascular disease in dogs with mucopolysaccharidosis VII. Circulation 2004; 110: 815-820.

$33 \mathrm{Xu}$ L, Mango RL, Sands MS, Haskins ME, Ellinwood NM, Ponder $\mathrm{KP}$ : Evaluation of pathological manifestations of disease in mucopolysaccharidosis VII mice after neonatal hepatic gene therapy. Mol Ther 2002; 6: 745-758.

$34 \mathrm{O}^{\prime}$ Malley T, Henthorn P, Xu L et al: Hematopoetic transduction in vivo by intravenous retroviral gene therapy in neonatal MPS VII dogs. Mol Ther 2003; 7: S82.

35 Haskins M, O'Malley T, Ellinwood NM et al: Intravenous retroviral gene therapy in seven-week-old dogs with mucopolysaccharidosis VII. Am J Hum Genet 2003; 73: S626.

36 Lynch CM: Gene therapy for hemophilia. Curr Opin Mol Ther 1999; 1: 493-499.

37 Brooks MB, Gu W, Barnas JL, Ray J, Ray K: A Line 1 insertion in the factor IX gene segregates with mild hemophilia B in dogs. Mamm Genome 2003; 14: 788-795.

38 Brooks MB, Gu W, Ray K: Complete deletion of factor IX gene and inhibition of factor IX activity in a labrador retriever with hemophilia B. J Am Vet Med Assoc 1997; 211: 1418-1421.

39 Cameron C, Notley C, Hoyle S et al: The canine factor VIII cDNA and 5' flanking sequence. Thromb Haemost 1998; 79: 317-322.

40 Evans JP, Brinkhous KM, Brayer GD, Reisner HM, High KA: Canine hemophilia $\mathrm{B}$ resulting from a point mutation with unusual consequences. Proc Natl Acad Sci USA 1989; 86: $10095-10099$

41 Evans JP, Watzke HH, Ware JL, Stafford DW, High KA: Molecular cloning of a cDNA encoding canine factor IX. Blood 1989; 74: 207-212.

42 Gallo-Penn AM, Shirley PS, Andrews JL et al: Systemic delivery of an adenoviral vector encoding canine factor VIII results in short-term phenotypic correction, inhibitor development, and biphasic liver toxicity in hemophilia A dogs. Blood 2001; 97: 107-113.

43 Hough C, Kamisue S, Cameron C et al: Aberrant splicing and premature termination of transcription of the FVIII gene as a cause of severe canine hemophilia A: similarities with the intron 22 inversion mutation in human hemophilia. Thromb Haemost 2002; 87: 659-665.

44 Lozier JN, Dutra A, Pak E et al: The Chapel Hill hemophilia A dog colony exhibits a factor VIII gene inversion. Proc Natl Acad Sci USA 2002; 99: 12991-12996.

45 Mauser AE, Whitlark J, Whitney KM, Lothrop Jr CD: A deletion mutation causes hemophilia B in Lhasa Apso dogs. Blood 1996; 88: $3451-3455$

46 Kay MA, Landen CN, Rothenberg SR et al: In vivo hepatic gene therapy: complete albeit transient correction of factor IX deficiency in hemophilia B dogs. Proc Natl Acad Sci USA 1994; 91: 2353-2357.

47 Herzog RW, Yang EY, Couto LB et al: Long-term correction of canine hemophilia B by gene transfer of blood coagulation factor IX mediated by adeno-associated viral vector. Nat Med 1999; 5: $56-63$.

48 Herzog RW, Mount JD, Arruda VR, High KA, Lothrop Jr CD: Muscle-directed gene transfer and transient immune suppression result in sustained partial correction of canine hemophilia B caused by a null mutation. Mol Ther 2001; 4: 192-200.

49 High KA: AAV-mediated gene transfer for hemophilia. Ann NY Acad Sci 2001; 953: 64-74.

50 Herzog RW, Fields PA, Arruda VR et al: Influence of vector dose on factor IX-specific T and B cell responses in muscle-directed gene therapy. Hum Gene Ther 2002; 13: 1281-1291.

51 Arruda VR, Stedman HH, Nichols TC et al: Regional intravascular delivery of AAV-2-F.IX to skeletal muscle achieves long-term 
correction of hemophilia B in a large animal model. Blood 2004; 105: $3458-3464$.

52 Harding TC, Koprivnikar KE, Tu GH et al: Intravenous administration of an AAV-2 vector for the expression of factor IX in mice and a dog model of hemophilia B. Gene Therapy 2004; 11: 204-213.

53 High KA: Adeno-associated virus-mediated gene transfer for hemophilia B. Int J Hematol 2002; 76: 310-318.

54 Snyder RO, Miao C, Meuse L et al: Correction of hemophilia B in canine and murine models using recombinant adeno-associated viral vectors. Nat Med 1999; 5: 64-70.

55 Mount JD, Herzog RW, Tillson DM et al: Sustained phenotypic correction of hemophilia B dogs with a factor IX null mutation by liver-directed gene therapy. Blood 2002; 99: 2670-2676.

$56 \mathrm{Xu} \mathrm{L}, \mathrm{Gao} \mathrm{C}$, Sands MS et al: Neonatal or hepatocyte growth factor-potentiated adult gene therapy with a retroviral vector results in therapeutic levels of canine factor IX for hemophilia B. Blood 2003; 101: 3924-3932.

57 Narfstrom K, Wrigstad A, Nilsson SE: The Briard dog: a new animal model of congenital stationary night blindness. $\mathrm{Br} \mathrm{J}$ Ophthalmol 1989; 73: 750-756.

58 Aguirre G, Baldwin D, Pearce-Kelling S, Narfstron K, Ray K, Acland GM: Congenital stationary night blindness in the dog: common mutation in the RPE65 gene indicates founder effect. Mol Vis 1998; 4: 23.

59 Wrigstad A, Nilsson SE, Narfstrom K: Ultrastructural changes of the retina and the retinal pigment epithelium in Briard dogs with hereditary congenital night blindness and partial day blindness. Exp Eye Res 1992; 55: 805-818.

60 Acland GM, Aguirre GD, Ray J et al: Gene therapy restores vision in a canine model of childhood blindness. Nat Genet 2001; 28: 92-95.

61 Bianco SR, Sun J, Fosmire SP et al: Enhancing antimelanoma immune responses through apoptosis. Cancer Gene Ther 2003; 10: $726-736$.

62 Chauvet AE, Kesava PP, Goh CS, Badie B: Selective intraarterial gene delivery into a canine meningioma. J Neurosurg 1998; 88: $870-873$.

63 Dow SW, Elmslie RE, Willson AP, Roche L, Gorman C, Potter TA: In vivo tumor transfection with superantigen plus cytokine genes induces tumor regression and prolongs survival in dogs with malignant melanoma. J Clin Invest 1998; 101: 2406-2414.

64 Hogge GS, Burkholder JK, Culp J et al: Development of human granulocyte-macrophage colony-stimulating factor-transfected tumor cell vaccines for the treatment of spontaneous canine cancer. Hum Gene Ther 1998; 9: 1851-1861.

65 Quintin-Colonna F, Devauchelle P, Fradelizi D et al: Gene therapy of spontaneous canine melanoma and feline fibrosarcoma by intratumoral administration of histoincompatible cells expressing human interleukin-2. Gene Therapy 1996; 3: $1104-1112$.

66 Thamm DH, Kurzman ID, Macewen EG et al: Intralesional lipidcomplexed cytokine/superantigen immunogene therapy for spontaneous canine tumors. Cancer Immunol Immunother 2003; 52: $473-480$.
67 Smith SH, Goldschmidt MH, McManus PM: A comparative review of melanocytic neoplasms. Vet Pathol 2002; 39: 651-678.

68 Berman AL: The Brainstem of the Cat: A Cytoarchitechtonic Atlas with Sterotactic Coordinates. Madison, WI: University of Wisconsin Press, 1968.

69 Berman AL: The Thalamus and Basal Telencephalon of the Cat: A Cytoarchitechtonic Atlas with Sterotactic Coordinates. Madison, WI: University of Wisconsin Press, 1982.

70 Jezyk PF, Haskins ME, Newman LR: Alpha-mannosidosis in a Persian cat. J Am Vet Med Assoc 1986; 189: 1483-1485.

71 Vite $\mathrm{CH}$, McGowan JC, Braund KG et al: Histopathology, electrodiagnostic testing, and magnetic resonance imaging show significant peripheral and central nervous system myelin abnormalities in the cat model of alpha-mannosidosis. J Neuropathol Exp Neurol 2001; 60: 817-828.

72 Berg T, Tollersrud OK, Walkley SU, Siegel D, Nilssen O: Purification of feline lysosomal alpha-mannosidase, determination of its cDNA sequence and identification of a mutation causing alpha-mannosidosis in Persian cats. Biochem J 1997; 328: 863-870.

73 Walkley SU, Thrall MA, Dobrenis $\mathrm{K}$ et al: Bone marrow transplantation corrects the enzyme defect in neurons of the central nervous system in a lysosomal storage disease. Proc Natl Acad Sci USA 1994; 91: 2970-2974.

74 Vite $\mathrm{CH}$, McGowan JC, Niogi SN et al: Effective gene therapy for an inherited CNS disease in a large animal model. Ann Neurol 2005; 57: 355-364.

75 Frisbie DD, Mcllwraith CW: Evaluation of gene therapy as a treatment for equine traumatic arthritis and osteoarthritis. Clin Orthop Relat Res 2000; 1 (379): S273-S287.

76 Frisbie DD, Ghivizzani SC, Robbins PD, Evans CH, McIlwraith CW: Treatment of experimental equine osteoarthritis by in vivo delivery of the equine interleukin-1 receptor antagonist gene. Gene Therapy 2002; 9: 12-20.

77 Robbins PD, Evans CH, Chernajovsky Y: Gene therapy for arthritis. Gene Therapy 2003; 10: 902-911.

78 Seltenhammer MH, Heere-Ress E, Brandt S et al: Comparative histopathology of grey-horse-melanoma and human malignant melanoma. Pigment Cell Res 2004; 17: 674-681.

79 Heinzerling LM, Feige K, Rieder S et al: Tumor regression induced by intratumoral injection of DNA coding for human interleukin 12 into melanoma metastases in gray horses. J Mol Med 2001; 78: $692-702$.

80 Harper PA, Healy PJ, Dennis JA: Animal model of human disease. Citrullinemia (argininosuccinate synthetase deficiency). Am J Pathol 1989; 135: 1213-1215.

81 Dennis JA, Healy PJ, Beaudet AL, O'Brien WE: Molecular definition of bovine argininosuccinate synthetase deficiency. Proc Natl Acad Sci USA 1989; 86: 7947-7951.

82 Msall M, Batshaw ML, Suss R, Brusilow SW, Mellits ED Neurologic outcome in children with inborn errors of urea synthesis. Outcome of urea-cycle enzymopathies. N Engl J Med 1984; 310: 1500-1505.

83 Lee B, Dennis JA, Healy PJ et al: Hepatocyte gene therapy in a large animal: a neonatal bovine model of citrullinemia. Proc Natl Acad Sci USA 1999; 96: 3981-3986. 